IRA-International Journal of Management \& Social Sciences

ISSN 2455-2267; Vol.03, Issue 03 (2016)

Institute of Research Advances

http://research-advances.org/index.php/RAJMSS

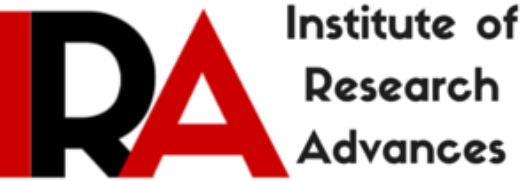

\title{
Organizational Culture in the Hospitality Sector: A Study of two organizations in Nagpur city
}

\author{
Ms. Parvin Shaikh, \\ Assistant Professor, \\ Datta Meghe Institute of Management Studies, Nagpur, India.
}

DOI: http://dx.doi.org/10.21013/jmss.v3.n3.p12

How to cite this paper:

Shaikh, P. (2016). Organizational Culture in the Hospitality Sector: A Study of two organizations in Nagpur city. IRA-International Journal of Management \& Social Sciences (ISSN 2455-2267), 3(3). doi:http://dx.doi.org/10.21013/jmss.v3.n3.p12

(C) Institute of Research Advances

(cc) EY-NC

This works is licensed under a Creative Commons Attribution-Non Commercial 4.0 International License subject to proper citation to the publication source of the work.

Disclaimer: The scholarly papers as reviewed and published by the Institute of Research Advances (IRA) are the views and opinions of their respective authors and are not the views or opinions of the IRA. The IRA disclaims of any harm or loss caused due to the published content to any party. 


\section{ABSTRACT}

Organizational culture refers to the common beliefs and values that are present in the organization which guides the behavior of its members. Organizational culture affects the way people and groups interact with each other, with clients, and with stakeholders. The main purpose of this paper is to study the OCTAPACE Culture at two different organizations belonging to Hospitality sector in Nagpur. The paper also aims to find out if there are differences in the culture of the two organizations. OCTAPACE profile instrument developed by Udai Pareek was used to study the cultural ethos at the selected organizations. Data analysis was done using SPSS. Findings indicate that the both the organizations scored within the normative values on five dimensions (Collaboration, Trust, Autonomy, Pro action, Confrontation), whereas one organization had excellent scores on two dimensions (Authenticity, Experimenting), the other scored below the lowest normative value on Openness.

Keywords: Organizational Culture, OCTAPACE, Hospitality Sector

\section{INTRODUCTION}

According to Edgar Schein ${ }^{20}$ (born 1928), a Professor at the MIT Sloan School of Management, "Organizational culture can be defined as a pattern of basic assumptionsinvented, discovered or developed by a given group as it learns to cope with its problems of external adaptation and internal integration-that has worked well enough to be considered valuable and, therefore, to be taught to new members as the correct way to perceive, think and feel in relation to those problems". Culture can be defined as the cumulative beliefs, values and assumptions, underlying transaction with nature and important phenomena. Culture includes the organization values, visions, norms, working language, systems, symbols, beliefs and habits. An organizational culture is usually passed on from the existing employees of the organization to the new recruits of the organizations by socializing with one another. Organizational culture affects the way people and groups interact with each other, with clients, and with stakeholders.

\section{LITERATURE REVIEW}

Culture Refers to something that is shared by all or almost all members of some social groups Adler (1986) ${ }^{2}$. Ouchi $(1981)^{9}$ defines organizational culture as Set of symbols, ceremonies and myths that communicate the underlying values and beliefs of the organization to its employees. According to Wood (2001) ${ }^{18}$, organizational culture is the systems of shared beliefs and values that develops within an organization or within its sub-units and that guides the behavior of its members. Ravasi and Schultz (2006) ${ }^{11}$ wrote that organizational culture is a set of shared assumptions that guide what happens in organizations by defining appropriate behavior for various situations. According to Needle (2004) ${ }^{8}$, organizational culture represents the collective values, beliefs and principles of organizational members and is a product of such factors as history, product, market, technology, and strategy, type of employees, management style, and national cultures and so on. Corporate culture on the other hand refers to those cultures deliberately created by management to achieve specific strategic ends. According to Hofstede $(1984)^{6}$, organizational culture refers to the collective programming of the mind that distinguishes the members of one organization from another..

Stewart (2007) ${ }^{15}$, stated that an organization's cultural norms strongly affect all who are involved in the organization. Those norms are almost invisible, but if we would like to improve performance and profitability, norms are one of the first places to look. George 
R. et $\mathrm{al}^{5}$, argues that certain organizational culture attributes add to the shaping of the behavior, productivity and personal effectiveness. They also add that organizational culture is the personality of the organization and it decides the employees' attitude and performance. Certain factors in organizational culture like trust, communication, information systems, rewards and organization structure are positively related to knowledge sharing in organizations. They play an important role in defining the relationships between staff and in turn, providing possibilities to break obstacles to knowledge sharing (Adel Ismail Al-Alawi et al, 2007) ${ }^{1}$. Luigi G. (2013) ${ }^{7}$ studied the dimensions of corporate culture which are related to a firm's performance. He found that when employees perceive top managers as trustworthy and ethical, firm's performance is stronger. Peters and Waterman $(1982)^{10}$ claimed that high performance firms could be distinguished from low performance firms because they possessed certain cultural traits and 'strong culture'. Similarly, Deal and Kennedy (1982) ${ }^{4}$ suggested that organizational performance can be enhanced by strong shared values. However, their suggestions were criticized by Carrol $(1982)^{3}$, Reyonds $(1986)^{13}$, and Saffold (1988) ${ }^{14}$ who commented that 'a simple model' relating organizational culture to performance no longer fits- a more sophisticated understanding of the tie between culture and performance must be developed. However, some researchers such as Wilderom and Berg (1998) ${ }^{17}$ argued that instead of striving for strong culture, researchers should attempt to reduce the gap between employees' preferred organizational culture practices and their perception of the organizational practices.

There is an association between organizational culture and the attitudes toward organizational change (Md Zabid Abdul Rashid) ${ }^{19}$. Organizational culture influences people's actions and behaviours. It also alters their actions in the perceptions of all aspects of their work including quality (Reeves and Bednar, 1994) ${ }^{12}$. A corporate culture aiming at continuous improvement and TQM is mentioned as an important factor that enhances the companies' capabilities, especially for innovation.

\section{STATEMENT OF THE PROBLEM:}

Organizational culture plays an important role in influencing the behavior of the employees with each other, towards the organization and also towards the stakeholders, thus affecting the Organization's performance. For an organization in the hospitality industry, it is important to have a culture which facilitates the desired behavior from the employees. The main purpose of this paper is to study the OCTAPACE Culture at two different organizations belonging to Hospitality sector in Nagpur. The paper also aims to find out if there are differences in the culture of the two organizations.

\section{RESEARCH OBJECTIVES:}

The present study has the following objectives-

1. To study the OCTAPACE Culture at the selected organizations

2. To find out the if there are differences among the organizations across the eight dimensions of OCTAPACE

\section{RESEARCH HYPOTHESES:}

The following null hypotheses were formulated-

$\mathbf{H}_{01}$ : Organizations under study are having excellent OCTAPACE Culture

$\mathbf{H}_{02}$ : Organizations under study do not differ significantly in their OCTAPACE Culture across the eight dimensions

$\mathbf{H}_{\text {02a }}$ : Organizations under study do not differ significantly in their Openness dimension 
$\mathbf{H}_{\mathbf{0 2 b}}$ : Organizations under study do not differ significantly in their Confrontation dimension

$\mathbf{H}_{\mathbf{0 2}}$ : Organizations under study do not differ significantly in their Trust dimension

$\mathbf{H}_{\mathbf{0 2 d}}$ : Organizations under study do not differ significantly in their Authenticity dimension

$\mathbf{H}_{\text {02e }}$ : Organizations under study do not differ significantly in their Pro-action dimension

$\mathbf{H}_{\mathbf{0 2 f}}$ : Organizations under study do not differ significantly in their Autonomy dimension

$\mathbf{H}_{\mathbf{0 2 g}}$ : Organizations under study do not differ significantly in their Collaboration dimension

$\mathbf{H}_{\mathbf{0 2 h}}$ : Organizations under study do not differ significantly in their Experimenting dimension

\section{RESEARCH METHODOLOGY:}

\subsection{Sample Selection}

The scope of the present study is limited to two organizations belonging to hospitality industry in Nagpur city (The names have not been mentioned to maintain confidentiality). For the purpose of the study, only the regular employees of the organization were considered. The sample size for the study was $\mathbf{8 0 .}$

\subsection{Research Design}

In order to fulfill the research objectives, OCTAPACE profile instrument developed by Udai Pareek was selected. OCTAPACE is $\mathrm{O}$ for Openness, $\mathrm{C}$ for Confrontation, $\mathrm{T}$ for Trust, A for Authenticity, P for Pro-action, A for Autonomy, C for Collaboration and E for Experimenting.

\subsection{Measures}

The OCTAPACE profile instrument was administered to the regular employees of the organization. The instrument consists of two parts. In the first part, values are stated in items 1 to 24 (three statements of each of the eight values), and the respondent is required to check (on a 4-point scale, where 4 stands for highly valued and 1 stands for very low value), how much each item is valued in his organization. Part 2 contains sixteen statements on beliefs ( 2 each for 8 values), and the respondent has to check (on a 4-point scale, where 4 stands for very widely shared belief and 1 stands for only few or none have this belief), how much each of them is shared in the organization. Reverse coding was done for total 9 items, which were negatively worded. These items are item no. 12, $22,25,26,28,30,31,35$ and 40 . After completing the data entry, total score for each value was compiled.

\subsection{Procedure}

First a permission letter was sent from the researcher to the HR Heads to carry forward this particular survey. A total of 100 questionnaires were distributed, out of which 80 responses were received for analysis with a response rate of $80 \%$.

\subsection{Data Analysis:}

The data was analyzed using Statistical Package for Social Sciences (20.0) version and the various analysis methods were conducted for this study including scale reliability analysis, descriptive statistics, and one way Anova. 


\section{DATA ANALYSIS AND INTERPRETATION:}

\subsection{Tests for reliability}

Table 1: Reliability

Statistics

\begin{tabular}{|r|r|}
\hline $\begin{array}{c}\text { Cronbach's } \\
\text { Alpha }\end{array}$ & N of Items \\
\hline .717 & 40 \\
\hline
\end{tabular}

For reliability analysis, Cronbach's alpha coefficient is widely used as a measurement value which describes how the data is close to normal distribution. A Cronbach's alpha value of 0.6 and above is normally considered as effective reliability for judging a scale (Flynn et al. 1994), which was later supported by Hair et al. (2010). In this study, the Cronbach's alpha coefficient was found to be 0.717 (Table 1) which indicates high reliability.

\subsection{Descriptive Statistics}

Table 2: Gender wise Description of the Respondents

\begin{tabular}{|c|l|c|c|}
\hline \multicolumn{2}{|c|}{} & Frequency & Percent \\
\hline \multirow{3}{*}{ Gender } & Male & 46 & 57.5 \\
\cline { 2 - 4 } & Female & 34 & 42.5 \\
\cline { 2 - 4 } & Total & 80 & 100.0 \\
\hline
\end{tabular}

Among the respondents were, 46 were male and 26 were females. Thus the gender distribution of the respondents was $57.5 \%$ males and $42.5 \%$ females.

Table 3: Tentative norms for OCTAPACE Profile

\begin{tabular}{|l|l|l|}
\hline Variables & Low & High \\
\hline Openness & 13 & 17 \\
\hline Confrontation & 10 & 16 \\
\hline Trust & 10 & 16 \\
\hline Authenticity & 10 & 14 \\
\hline Pro action & 12 & 18 \\
\hline Autonomy & 11 & 16 \\
\hline Collaboration & 13 & 17 \\
\hline Experimenting & 11 & 16 \\
\hline
\end{tabular}

Source: Udai Pareek (2002)

\subsection{Inferential Statistics}

$\mathbf{H}_{01}$ : Organizations under study are having excellent OCTAPACE Culture

Following is the table showing comparative analysis of organizations for OCTAPACE dimensions for Middle management Personnel as per the above-mentioned norms. Scores below 'low value' shown in the Norms table are rated as 'requires improvement'; scores above 'high value' are rated as 'excellent' and scores between low and high value are rated as 'very good'. 
Table 4: Comparative Analysis of Organizations for OCTAPACE Dimensions

\begin{tabular}{|l|l|l|}
\hline Variables & Organization A & Organization B \\
\hline Openness & $\begin{array}{l}12.525 \text { (Requires } \\
\text { improvement) }\end{array}$ & 14.2 (Very good) \\
\hline Confrontation & 12.7 (Very good) & 13.9 (Very good) \\
\hline Trust & 13.3 (Very good) & 14.7 (Very good) \\
\hline Authenticity & 12.475 (Very good) & 14 (Excellent) \\
\hline Pro action & 13 (Very good) & $\begin{array}{l}13.125 \text { (Very } \\
\text { good) }\end{array}$ \\
\hline Autonomy & 14.2 (Very good) & $\begin{array}{l}15.075 \text { (Very } \\
\text { good) }\end{array}$ \\
\hline Collaboration & 13.575 (Very good) & $\begin{array}{l}14.95 \text { (Very } \\
\text { good) } \\
16.025 \\
\text { (Excellent) }\end{array}$ \\
\hline Experimenting & 14.9 (Very good) & \multicolumn{2}{|l}{}
\end{tabular}

For Organization A, OCTAPACE culture was found to be 'very good' for 7 dimensions, whereas for 'Openness' dimension it was found to be 'requires improvement'. Therefore the hypothesis is rejected for all the dimensions. For Organization B, OCTAPACE culture was found to be 'Excellent' for two dimensions, i.e., 'Authenticity' \& 'Experimenting'. For the remaining six dimensions, it was 'very good'. Hence the hypothesis was accepted for 'Authenticity' \& 'Experimenting' dimensions and rejected for the remaining.

$\mathbf{H}_{\mathbf{0 2}}$ : Organizations under study do not differ significantly in their OCTAPACE Culture across the eight dimensions.

The hypothesis was tested using one way Anova.

\begin{tabular}{|c|c|c|c|c|c|c|}
\hline \multicolumn{7}{|c|}{ Table 5: ANOVA } \\
\hline & & $\begin{array}{c}\text { Sum of } \\
\text { Squares }\end{array}$ & $\mathrm{df}$ & Mean Square & $\mathrm{F}$ & Sig. \\
\hline \multirow{3}{*}{ Openness } & Between Groups & 56.112 & 1 & 56.112 & 15.073 & .000 \\
\hline & Within Groups & 290.375 & 78 & 3.723 & & \\
\hline & Total & 346.487 & 79 & & & \\
\hline \multirow{3}{*}{ Confrontation } & Between Groups & 32.513 & 1 & 32.513 & 15.475 & .000 \\
\hline & Within Groups & 163.875 & 78 & 2.101 & & \\
\hline & Total & 196.388 & 79 & & & \\
\hline \multirow{3}{*}{ Trust } & Between Groups & 39.200 & 1 & 39.200 & 15.859 & .000 \\
\hline & Within Groups & 192.800 & 78 & 2.472 & & \\
\hline & Total & 232.000 & 79 & & & \\
\hline \multirow{3}{*}{ Authenticity } & Between Groups & 46.513 & 1 & 46.513 & 17.962 & .000 \\
\hline & Within Groups & 201.975 & 78 & 2.589 & & \\
\hline & Total & 248.488 & 79 & & & \\
\hline \multirow{3}{*}{ Pro action } & Between Groups & .313 & 1 & .313 & .270 & .605 \\
\hline & Within Groups & 90.375 & 78 & 1.159 & & \\
\hline & Total & 90.688 & 79 & & & \\
\hline
\end{tabular}


IRA-International Journal of Management \& Social Sciences

\begin{tabular}{|l|l|r|r|r|r|r|}
\hline \multirow{3}{*}{ Autonomy } & Between Groups & 15.313 & 1 & 15.313 & 11.356 & .001 \\
& Within Groups & 105.175 & 78 & 1.348 & & \\
& Total & 120.487 & 79 & & & \\
\hline \multirow{3}{*}{ Collaboration } & Between Groups & 37.813 & 1 & 37.813 & 18.020 & .000 \\
& Within Groups & 163.675 & 78 & 2.098 & & \\
& Total & 201.488 & 79 & & & \\
\hline \multirow{3}{*}{ Experimenting } & Between Groups & 25.312 & 1 & 25.312 & 19.631 & .000 \\
& Within Groups & 100.575 & 78 & 1.289 & & \\
& Total & 125.887 & 79 & & & \\
\hline
\end{tabular}

From the above table, it can be seen that the $\mathrm{p}$ values for the dimensions openness (0.000), confrontation (0.000), trust (0.000), authenticity (0.000), autonomy (0.001), collaboration (0.000) and experimenting (0.000) are less than the level of significance 0.05. The p- value for dimension Pro-action (0.605) is greater than 0.05, the level of significance. Thus, hypothesis $\mathbf{H}_{02 \mathrm{a}}, \mathbf{H}_{\mathbf{0 2 b}}, \mathbf{H}_{\mathbf{0 2 \mathrm { c }}}, \mathbf{H}_{\mathbf{0 2 \mathrm { d }}}, \mathbf{H}_{\mathbf{0 2 \mathrm { f }}}, \mathbf{H}_{\mathbf{0 2 \mathrm { g }}}$ and $\mathbf{H}_{\mathbf{0 2 \mathrm { h }}}$ can be rejected,

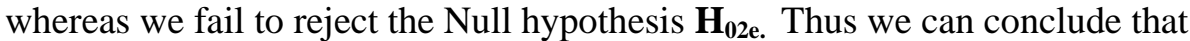

\section{CONCLUSION:}

From the above study it can be concluded that Organization A needs to focus on the dimension of 'Openness' as 'it needs improvement' as per the norms given by Udai Pareek. As far the other dimensions are concerned, they are 'very good'. No dimension has been found to be excellent in Organization A. Therefore Hypothesis 1 is rejected for all dimensions in case of Organization A. For Organization B, OCTAPACE culture was found to be 'Excellent' for 'Authenticity' \& 'Experimenting', whereas it was found to be 'very good' for other dimensions. Hence hypothesis 1 was accepted for 'Authenticity' \& 'Experimenting' and rejected for the remaining dimensions.

The results of Anova show that there are significant differences between the two organizations across the Openness, Confrontation, Trust, Authenticity, Autonomy, Collaboration and Experimenting dimensions. Hence Hypothesis 2a, Hypothesis 2b, Hypothesis 2c, Hypothesis 2d, Hypothesis 2f, Hypothesis 2g, Hypothesis $2 \mathrm{~h}$ have been rejected. However, we fail to reject Hypothesis $2 \mathrm{e}$, as the table shows that there is no significant difference between the two organizations in their Pro-action dimension of OCTAPACE Culture. This indicates that Organizations may have similarity on some dimensions, as they belong to the same sector, but individual differences do prevail.

\section{References:}

1. Adel Ismail Al-Alawi, Nayla Yousif Al-Marzooqi and Yasmeen Fraidoon Mohammed (2007), 'Organizational culture and knowledge sharing: Critical Success Factors', Journal Of Knowledge Management, Vol. 11 No. 2, pp. 22-42

2. Adler. N. J., Doktor, R., and Redding, S. G. (1986), 'From the Atlantic to the Pacific century. Cross-cultural management reviewed', Journal of Management, 12, pp. 295318.

3. Carroll, D.T. (1982), 'A disappointing Search for Excellence', Harvard Business Review, (6), p78-88.) 
4. Deal T. E. and Kennedy, A. A. (1982, 2000), 'Corporate Cultures: The Rites and Rituals of Corporate Life', Harmondsworth, Penguin Books, 1982; reissue Perseus Books, 2000

5. George R., Jayan C., 'Perceptions of organizational culture and personal effectiveness: A Meta analytical study' obtained from http://www.academia.edu/1481539/Perceptions of organizational culture and perso nal_effectiveness_A_Meta_analytical_study

6. Hofstede, G. (1984). 'Cultural Consequences: International Differences in Work Values’, Sage, Beverly Hills.

7. Luigi G. (2013), 'Value of Corporate Culture', Journal of Financial Economics, http://economics.mit.edu/files/9721

8. Needle, D. (2004), 'Business in context: An introduction to Business and Its Environment', ISBN 978 - 1861529923.

9. Ouchi, W. (1981), 'Theory Z'. Reading, MA: Addison-Wesley

10. Peters, Tom, and Robert Waterman (1982), 'In Search of Excellence: Lessons from America's Best Run Companies', New York: Harper and Row

11. Ravasi, D. and Schultz, M. (2006): "Responding to organizational identity threats: Exploring the role of organizational culture". Academy of Management Journal 49(3): 433-458.

12. Reeves, C.A., Bednar, D.A. (1994), 'Defining quality: Alternatives and implications', Academy of Management Review, 19, 419-445.

13. Reynolds, P. D. (1986), 'Organizational Culture as Related To Industry, Position and Performance: A Preliminary Report', Journal of Management Studies, 23: 333-345.

14. Saffold, G.S. (1988), 'Culture traits, strength, and organizational performance: moving beyond strong culture', Academy of Management Review, Vol. 13 No. 4, pp. 546-58

15. Stewart Douglas (2007), 'Growing the corporate culture'

16. Udai Pareek, Training Instruments in HR \& OD, Mcgraw Hill Education, Second Edition

17. Wilderom, C. P. M. \& Van den Berg, P. T. (1998), 'A Test of the Leadership-CulturePerformance Model within a Large Dutch Financial Organization', S. Havlovic. Ed. Best Paper Proceedings, Annual Meeting of the Academy of Management, San Diego, CA

18. Wood, J., Wallace, J., Zeffane, R.M., Schermerhorn, J.R., Hunt, J.G. \& Osborn, R.N. (2001), 'Organizational Behaviour: A Global Perspective', (2nd edition), John Wiley \& Sons: Milton, Queensland. 
19. Z Abdul Rashid, M Sambasivan, A Abdul Rahman (2004), 'The influence of organizational culture on attitudes toward organizational change', Leadership \& Organization Development Journal, Vol. 25, Issue 2, pg. 161-179.

20. http://academlib.com/3030/management/organiational_culture 